\title{
Suppression of autophagic activation in the mouse uterus by estrogen and progesterone
}

\section{Soyoung Choi, Hyejin Shin, Haengseok Song' and Hyunjung Jade Lim}

Department of Biomedical Science and Technology, Institute of Biomedical Science and Technology, Konkuk University, 120 Neungdong-ro, Gwangjin-gu, Seoul 143-701, Korea

${ }^{1}$ Department of Biomedical Science, College of Life Science, CHA University, Seoul 135-081, Korea
Correspondence should be addressed to H Song or H J Lim Emails hssong@cha.ac.kr or hlim@konkuk.ac.kr

\begin{abstract}
Autophagy is a major cellular catabolic pathway tightly associated with cell survival. The involvement of autophagy in the prolonged survival of blastocysts in the uterus is well established, and it was assumed that ovarian steroid hormones - progesterone $\left(\mathrm{P}_{4}\right)$ and estrogens - have important roles in the regulation of autophagy. However, information is scarce regarding whether these hormones regulate autophagy in certain hormoneresponsive cellular systems. In this study, we investigated the effects of estrogen and $\mathrm{P}_{4}$ on autophagic response in the uteri of pregnant mice and in ovariectomized (OVX) mice treated with hormones. During pregnancy, autophagic response is high on days 1 and 2 when the uterus shows an inflammatory response to mating, but it subsides around the time of implantation. Dexamethasone treatment to day 1 pregnant mice reduced autophagy in the uterus. In OVX mouse uteri, estrogen or $\mathrm{P}_{4}$ reduces autophagic response within $6 \mathrm{~h}$. Glycogen content in OVX uteri was increased by 3-methyladenine treatment, suggesting that autophagy is involved in glycogen breakdown in the hormone-deprived uterus. The classical nuclear receptor antagonists, ICI 182780 or mifepristone, lead to the recovery of the autophagic response in OVX uteri. The suppression of autophagy by $17 \beta$-estradiol is inversely correlated with the accumulation of phospho-mouse target of rapamycin, and rapamycin treatment is moderately effective in the upregulation of autophagic response in OVX mouse uteri. Collectively, this study establishes that the uterine autophagy is induced in hormone-derived environment and is suppressed by hormone treatment. Uterine autophagy may have multiple functions as a responsive mechanism to acute inflammation and as an energy provider by breaking down glycogen under hormone deprivation.
\end{abstract}

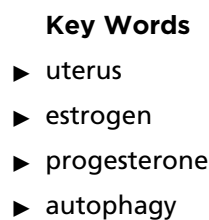

Journal of Endocrinology (2014) 221, 39-50

\section{Introduction}

The uterus is an important hormone-responsive reproductive organ in mammals. Histologically, the uterus is composed of three major cell types: epithelial cells, stromal cells, and myometrial cells. Epithelial and stromal cells together form the endometrium (Dey \& Lim 2006). The innermost layer is a simple columnar epithelium and this layer is connected to numerous uterine glands. Underneath the epithelium, there is a loose connective tissue layer with stromal cells, glands, and blood vessels. Many uterine functions are under the regulation of ovarian steroid hormones, estrogens and progesterone ( $\mathrm{P}_{4}$; Dey et al. 2004, Das 2009), and uterine cell types http://joe.endocrinology-journals.org DOI: 10.1530/JOE-13-0449
C 2014 Society for Endocrinology Printed in Great Britain
Published by Bioscientifica Ltd 
respond to hormones in a differential manner. Ovarian estrogen targets uterine epithelial cells, inducing proliferation and differentiation of these cells, whereas the proliferation of uterine stromal cells is under $\mathrm{P}_{4}$ regulation. Thus, $\mathrm{P}_{4}$ and estrogen are essential mediators of cell survival and maintenance in the uterus (Dey et al. 2004, Dey \& Lim 2006).

Mice typically have an estrous cycle of 3-4 days. The cycle is due to the periodic changes in gonadotropins and steroid hormones. Each phase of the estrous cycle can be confirmed by cellular changes in the vaginal lining (Whitten 1958). A preovulatory estrogen surge induces epithelial cell proliferation in the uterus and causes ovulation. As estrogen levels fall, $\mathrm{P}_{4}$ is secreted from corpora lutea in the ovary and induces proliferation of uterine stromal cells. $\mathrm{P}_{4}$ secretion is maintained during early pregnancy and a small amount of estrogen is secreted on day 4 of pregnancy (Dey et al. 2004). Together, these hormones prepare the uterus for embryo implantation, a process that begins around midnight of day 4 of pregnancy. Thus, $\mathrm{P}_{4}$ and estrogen are crucial regulators of cell cycle and cellular differentiation in the uterus (Das 2009).

Autophagy is a major cellular bulk degradation pathway in cells (Levine \& Klionsky 2004). Cells usually maintain a basal level of autophagy, but harsh environments, such as lack of growth factors and nutrients, cause a higher level of autophagic response (Yang \& Klionsky 2010, Boya et al. 2013). Autophagy-related (Atg) proteins are involved in the intricate cellular processes of autophagosome formation and their fusion with lysosomes (Boya et al. 2013). During autophagosomal vesicle elongation and completion, Atg7 (E1-like enzyme) and Atg10 (E2-like enzyme) mediate conjugation of Atg5 and Atg12, while conjugation of phosphatidylethanolamine (PE) with a glycine residue of LC3 (Atg8) is mediated by another Atg protein complex (Glick et al. 2010). Lipid conjugation leads to the conversion of the soluble form, LC3-I, to the autophagic membrane-associated form, LC3-II. Thus, the accumulation of LC3-II within cells is widely used as a marker of autophagic activation (Klionsky et al. 2012).

We previously showed that mouse blastocysts show heightened autophagy when implantation is delayed by ovariectomy (OVX) on day 4 of pregnancy (Lee et al. 2011). Under conditions of estrogen deprivation, dormant blastocysts survive in utero while the uterine quiescence is maintained by daily $\mathrm{P}_{4}$ injection (Dey \& Lim 2006). Dormant blastocysts exhibit heightened levels of autophagy during their prolonged survival in estrogendeprived delayed implanting uteri (Lee et al. 2011).
In preimplantation mouse embryos, endocannabinoids are established inducers of autophagy (Oh et al. 2013). In human endometrial cells, autophagy seems to be involved in the cell cycle (Choi et al. 2012). However, whether ovarian steroid hormones regulate autophagic response in the mouse uterus has not been established. We hypothesize that ovarian steroid hormones, sitting at the upstream of signaling mediators regulating the various aspects of uterine physiology, may serve as signaling regulators of autophagy. Here, we tested this hypothesis in normal pregnant mice and in OVX mice treated with either $17 \beta$-estradiol $\left(\mathrm{E}_{2}\right)$ or $\mathrm{P}_{4}$. The results show that both estrogen and $\mathrm{P}_{4}$ are potential negative regulators of autophagic response in the mouse uterus.

\section{Materials and methods}

\section{Animals}

Five- or six-week-old virgin ICR mice were purchased from Orient-Bio (Gyunggi-do, Korea). GFP-LC3 transgenic mice were obtained from the RIKEN BioResource Center (Ibaraki, Japan) (Mizushima et al. 2004). Mice were housed in a controlled barrier facility in the Laboratory Animal Research Center, Konkuk University. This study was approved by the Institutional Animal Care and Use Committee (IACUC, approval number KU12109). Female mice were bred with stud male mice and the vaginal plugs were examined the following morning. When plugs were noted in the morning, it was designated as day 1 of pregnancy. Uteri were collected on days 1, 2, 4, 5, and 8 of pregnancy. Day 8 pregnant mouse uteri were divided into two parts: the decidual portion containing embryo and the myometrial layer. Randomly cycling ICR mice were OVX at $0930 \mathrm{~h}$ for steroid hormonal deprivation. After 12 days of rest, hormone was administered subcutaneously; $\mathrm{P}_{4}$ was given at $1 \mathrm{mg} / 0.1 \mathrm{ml}$ sesame oil and $\mathrm{E}_{2}$ at $100 \mathrm{ng} / 0.1 \mathrm{ml}$ sesame oil. A control group of OVX mice received $0.1 \mathrm{ml}$ of sesame oil. Uteri were taken from OVX mice at the indicated times after hormone injection. For the dexamethasone (DEX) experiment, day 1 pregnant mice received a single i.p. injection of DEX $(2.5 \mathrm{mg} / \mathrm{kg}$ body weight) (Kim et al. 2004) at $0800 \mathrm{~h}$ on day 1 and killed at $2000 \mathrm{~h}$. Control mice received $0.1 \mathrm{ml}$ of PBS. Uteri were collected and subjected to LC3 western blotting.

\section{Reagents}

The following antibodies were used: anti-LC3 (Ab48394, Abcam, Cambridge, MA, USA), anti-p62 (BD610832,

Published by Bioscientifica Ltd. 
BD Biosciences, Franklin Lakes, NJ, USA), anti-Beclin1 (NB500-249, Novus Biologicals, Littleton, CO, USA), anti-Atg5 (NB110-53818, Novus), and anti-tubulin (Sigma-Aldrich). Antibodies for $\alpha$-tubulin and $\beta$-tubulin were mixed as 1:1 ratio and used in western blotting. Both $\mathrm{P}_{4}$ and $\mathrm{E}_{2}$ were purchased from Sigma-Aldrich and dissolved in sesame oil (Acros Organics, Fisher Scientific, St Louis, MO, Korea). ICI 182780 is an estrogen receptor (ER) antagonist and was purchased from Tocris Bioscience (no.1047, Bristol, UK). Mifepristone, a $\mathrm{P}_{4}$ receptor (PR) antagonist, was purchased from Sigma-Aldrich and Rapamycin from Calbiochem (Seoul, Korea). For in vivo experiments, ICI 182780 and mifepristone were dissolved in ethanol and diluted to $0.5 \mathrm{mg} / 0.1 \mathrm{ml}$ PBS and $1 \mathrm{mg} / 0.1 \mathrm{ml}$ PBS respectively (Das et al. 1995, 1997). Rapamycin was first dissolved in dimethyl sulfoxide, then diluted in PBS, and given to OVX mice at $5 \mathrm{mg} / \mathrm{kg}$ body weight before hormone injection.

\section{Preparation of uterine protein extracts}

Protein extraction and western blotting were carried out as described previously (Oh et al. 2013). Uteri were removed at the indicated times and the protein extraction was carried out in lysis buffer $(10 \mathrm{mM}$ Tris (pH 7.2), $150 \mathrm{mM} \mathrm{NaCl}, 0.1 \%$ Triton X-100, 5 mM EDTA, $1 \%$ SDS, $1 \mathrm{mM}$ dithiothreitol (DTT), and $1 \mathrm{mM}$ phenylmethylsulphonyl fluoride (PMSF)). An aliquot of Complete Protease Inhibitor Cocktail (Roche) was added to the lysate. Collected uteri were cut into 10-mm segments and homogenized with a Polytron homogenizer in the lysis buffer. Lysates were centrifuged at $12600 \boldsymbol{g}$ for $20 \mathrm{~min}$ at $4{ }^{\circ} \mathrm{C}$. The supernatant was isolated and BCA protein assay (Thermo Fisher Scientific, Rockford, IL, USA) was used to assess the protein concentration.

\section{Western blotting}

Fifty micrograms of each protein sample was loaded onto a 12\% SDS-polyacrylamide gel and blotted on PVDF or nitrocellulose membrane (Millipore, Billerica, MA, USA). The membranes were blocked with $5 \%$ skimmed milk in TBS for $1 \mathrm{~h}$ and incubated with primary antibody at $4{ }^{\circ} \mathrm{C}$ overnight. The membranes were incubated with peroxidase-conjugated secondary antibodies (GenDEPOT, Barker, TX, USA) diluted to 1:10000 for $1 \mathrm{~h}$. Chemiluminescence signal was detected using a LAS3000 imaging system (Fujifilm, Tokyo, Japan).

\section{RNA extraction and RT-PCR}

Total RNA extraction was carried out with Trizol Reagent (Molecular Research Center, Cincinnati, OH, USA), following manufacturer's protocol. RNA concentration was measured using spectrophotometer. RNA $(2.5 \mu \mathrm{g})$ and $1 \mu \mathrm{l}$ of oligo dT primer were added to a total reaction volume of $12 \mu \mathrm{l}$. After incubation for $5 \mathrm{~min}$ at $70^{\circ} \mathrm{C}$, the samples were moved to $4{ }^{\circ} \mathrm{C}$. RT was carried out in a total volume of $40 \mu \mathrm{l}$ containing $8 \mu \mathrm{l} 5 \times$ RT buffer, $4 \mu \mathrm{l} 0.1 \mathrm{M}$ DTT, $2 \mu \mathrm{l} 10 \mathrm{mM}$ dNTP, $1 \mu \mathrm{l}$ RTase, and $13 \mu \mathrm{l}$ water. Primers are shown in Supplementary Table S1, see section on supplementary data given at the end of this article.

\section{Immunofluorescence staining and confocal microscopy}

Uteri were cut into $4-5 \mathrm{~mm}$ pieces and fixed in $4 \%$ paraformaldehyde (PFA) in PBS overnight. After fixation, the uterine tissues were embedded in $30 \%$ sucrose solution and frozen with optimal cutting temperature (OCT) compound (Leica Microsystems, Wetzlar, Germany). Frozen tissue blocks were sectioned at $10 \mu \mathrm{m}$ and mounted on glass slides. Tissue sections were fixed and permeabilized with acetone for $20 \mathrm{~min}$ at room temperature. The tissue sections were blocked with $2 \%$ goat serum in PBS for $60 \mathrm{~min}$ at room temperature and incubated with anti-LC3 antibody in $2 \%$ goat serum in PBS at $4{ }^{\circ} \mathrm{C}$ overnight. Alexa Fluor 488-conjugated secondary antibody (Invitrogen) in $2 \%$ goat serum in PBS was added to the sections for $40 \mathrm{~min}$ at room temperature in the dark. Counterstaining of DNA was carried out with TO-PRO-3-iodide (Invitrogen) in PBS for $20 \mathrm{~min}$ in the dark. The slides were mounted with Antifade mounting medium (Invitrogen) and sealed with transparent nail polish. Immunofluorescence images were obtained using the Olympus TM Fluoview FV1000 Confocal Microscope at wavelengths of 488 and $633 \mathrm{~nm}$.

\section{GFP-LC3 live imaging}

Three-month-old GFP-LC3 ${ }^{\mathrm{Tg} /+}$ female mice (Mizushima et al. 2004) were OVX and received $\mathrm{E}_{2}$ or oil injection after 12 days of rest ( $n=2$ each). Mice were perfused with $4 \%$ PFA in PBS under anesthesia for $12 \mathrm{~h}$ after hormone injection. Uteri were collected and fixed overnight (Marino et al. 2007). Uterine pieces were transferred to $15 \%$ sucrose in PBS the following day and incubated for $4 \mathrm{~h}$. Uterine pieces were then transferred to $30 \%$ sucrose solution for overnight incubation. Tissue samples were embedded in OCT compound and stored in $-70^{\circ} \mathrm{C}$. The samples were sectioned at $5 \mu \mathrm{m}$ of thickness with cryostat. The slides

Published by Bioscientifica Ltd. 
were air-dried for $1 \mathrm{~h}$ and washed in PBS for $5 \mathrm{~min}$. The slides were further dried at room temperature for $30 \mathrm{~min}$ and then mounted with Antifade mounting medium.

\section{Transmission electron microscopy}

To examine the ultrastructural changes, uterine pieces from oil-treated OVX mice were fixed with $2.5 \%$ glutaraldehyde (Sigma-Aldrich) in PBS for $2 \mathrm{~h}$ at room temperature and were washed with fresh PBS. The tissue pieces were placed in agar chips and were postfixed in 1\% osmium tetroxide (Sigma-Aldrich) in PBS for $1 \mathrm{~h}$. After dehydration and infiltration, the tissue pieces were embedded in Epon 812. Tissue blocks were cut with a diamond knife (Diatome, Biel, Switzerland) and were placed on copper grids. The sections were double-stained with uranyl acetate and lead citrate and examined under a H-7650 transmission electron microscope (Hitachi).

\section{Glycogen assay}

Glycogen content in mouse uteri was quantified using Glycogen Fluorometric Assay Kit (Ab65620, Abcam). Uteri were collected from OVX mice $(n=3)$ treated with oil or $E_{2}(12 \mathrm{~h})$. Some OVX mice received daily injection of 3-methyladenine (3-MA) ( $0.1 \mathrm{ml}$ of $5 \mathrm{mM}$ solution in PBS) at $0930 \mathrm{~h}$ for 5 days before kill. Uteri were homogenized with Polytron homogenizer in $200 \mu$ l of distilled water. The homogenates were boiled for $5 \mathrm{~min}$ and spun for $5 \mathrm{~min}$ at $12600 \mathrm{~g}$. One microliter of the supernatant was subjected to glycogen quantitation following manufacturer's protocol. Each sample was run in duplicate.

\section{Isolation and culture of mouse uterine stromal and epithelial cells}

Cells were isolated from the uteri of random cycling mice $(n=6)$ (Chung \& Das 2011). Uterine horns were dissected, slit longitudinally, and cut into $3-4 \mathrm{~mm}$ pieces. The isolation of uterine cells was carried out with pancreatin (Sigma-Aldrich), dispase (Invitrogen), and collagenase, following the procedure of Chung \& Das (2011). Uterine epithelial cells and stromal cells were cultured separately in DMEM:F-12 (1:1) media with antibiotics and $10 \%$ charcoal-stripped fetal bovine serum (FBS) (Sigma-Aldrich). The cell culture medium was changed every other day until the cells reached $\sim 80 \%$ confluence. Before hormone treatment, media were replaced with phenol red-free Hank's Balanced Salt solution (HBSS) (14025-092, Gibco). After $1 \mathrm{~h}$ in HBSS, the cells were treated with $\mathrm{E}_{2}$ or $\mathrm{P}_{4}$ for $2 \mathrm{~h}$. The cells were then subjected to western blotting.

\section{Statistical analysis}

Chemiluminescence signals were quantified using the LAS3000 system and Multi Gauge software (Fujifilm). The LC3-II signal was normalized against anti-tubulin signal. Statistical analysis was carried out using the GraphPad Prism software (GraphPad Software, Inc., La Jolla, CA, USA).

\section{Results}

\section{The status of autophagy in mouse uteri during the peri-implantation period}

The pregnant mouse uterus is under the dynamic influence of $\mathrm{P}_{4}$ and $\mathrm{E}_{2}$ during the peri-implantation period (Das 2009). The level of $\mathrm{E}_{2}$ is the highest on day 1 and is decreased by day 3. $\mathrm{P}_{4}$ gradually increases from day 3 onward. On day 4 , a small amount of estrogen is secreted along with $\mathrm{P}_{4}$. After implantation on day 4 night, $\mathrm{P}_{4}$ is the major hormone maintaining the state of pregnancy in the uterus. We assessed autophagy in pregnant mouse uteri by LC 3 western blotting first. The amount of the lipidated LC3-II form reflects the status of autophagy in cells and tissues (Geng \& Klionsky 2008, Klionsky et al. 2012). As shown in Fig. 1A, the highest levels of LC3-II were observed in uteri during days 1 and 2 of pregnancy. This level gradually falls as $\mathrm{P}_{4}$ becomes predominant on day 4. LC3-II is detected at low levels on days 5 and 8 . These observations suggest that autophagic response exhibits a dynamic pattern in the peri-implantation mouse uteri. We also carried out western blotting of other autophagy markers, such as p62, Beclin 1 (Becn1, Atg6), and Atg5. p62, an ubiquitin-associated protein, interacts with LC3 and is a selective substrate for autophagy (Komatsu \& Ichimura 2010). Accumulation of p62 is associated with decreased autophagy (Komatsu et al. 2007). As shown in Fig. 1B, the level of p62 increases from day 4 , which is inversely correlated with LC3-II conversion in the peri-implantation mouse uterus (Fig. 1A). Although the decreased LC3-II and increased p62 show significant reduction of autophagic activation from day 4 onward, the levels of BECN1 and ATG5 proteins maintain steady-state levels during this period (data not shown).

Having observed the highest levels of LC3-II in the uteri of pregnant mice on days 1 and 2 , we examined which cell types exhibited predominant accumulation of LC3 by immunofluorescence staining. By immunofluorescence staining, LC3-II form appears as puncta in the cytoplasm,

Published by Bioscientifica Ltd 

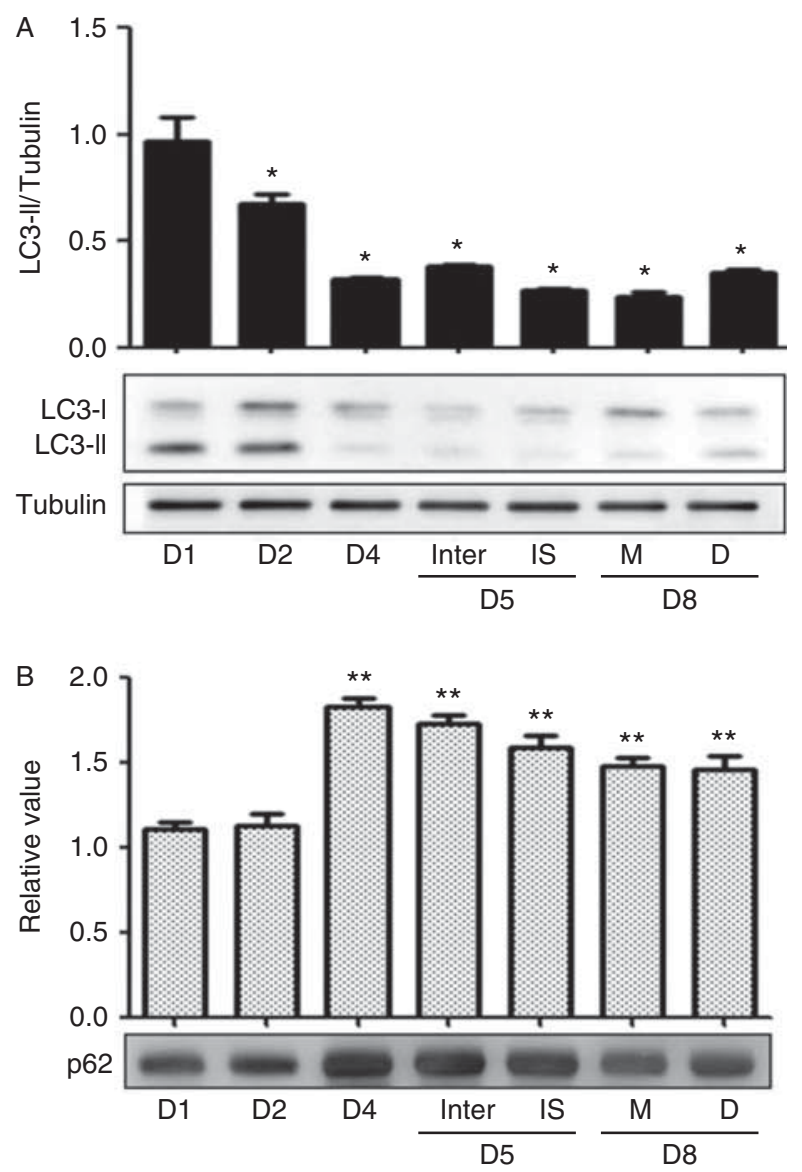

Figure 1

Autophagic activation assessed by western blotting of LC3 and p62 in periimplantation mouse uteri. (A) LC3 western blot analysis of pregnant mouse uteri on days $1,2,4,5$, and 8 . Day 5 uteri were divided into implantation sites (IS) and inter-implantation sites (Inter). Day 8 uteri were divided into decidual plus embryo ( $D$, decidua) and myometrium (M). A total of $50 \mu \mathrm{g}$ protein was loaded on each lane. The ratio of LC3-II signal/tubulin signal was used to analyze the data. The normalized value of day 1 was set as 1 and the relative values of the other group were plotted. Data show the mean of three independent experiments. (B) p62 western blot analysis of pregnant mouse uteri on days $1,2,4,5$, and 8 . A total of $50 \mu \mathrm{g}$ protein was loaded on each lane. Data show the mean of three independent experiments. Error bars represent S.D. Statistical significance was analyzed between $\mathrm{D} 1$ and each sample. ${ }^{*} 0.01<P<0.05 ;{ }^{* * P}<0.01$. D1, day 1 pregnant uteri; D2, day 2 pregnant uteri; D4, day 4 pregnant uteri; D5, day 5 pregnant uteri; D8, day 8 pregnant uteri; IS, implantation sites; Inter, inter-implantation sites; M, myometrium; D, decidua and embryo.

indicating their accumulation in autophagosomes and autophagolysosomes (Lee et al. 2011). As shown in Fig. 2A, subsets of stromal cells showed an intense signal of LC3 puncta in the day 1 pregnant uterus. Upon magnification, LC3 signal is accumulated near the nuclei of some stromal cells. In contrast, LC3-positive cells were observed at a much lower level in day 4 pregnant uteri. This experiment clearly shows that stromal cells are the major site of autophagic activation on day 1 of pregnancy.
One distinguishable event that occurs on day 1 of pregnancy is the infiltration of immune cells in response to the production of various cytokines in the uterus (McMaster et al. 1992). This inflammatory response is mainly due to semen deposition during mating (Robertson et al. 1994). Production of cytokines during inflammation is shown to induce autophagosome formation during inflammatory response in other systems (Harris 2013). Thus, we hypothesized that acute inflammatory response triggered by mating is one inducer of autophagy in the day 1 pregnant uterus. To test this hypothesis, DEX, a widely used anti-inflammatory compound, was injected to day 1 pregnant mice on the morning of finding the vaginal plug (Kim et al. 2004). The uteri from DEX- or PBS (vehicle)-injected mice were subjected to LC3 western blotting. As shown in Fig. 2B, DEX-injected mice show significantly reduced LC3-II conversion in the uterus compared with PBS-injected control mice. This result suggests that inflammatory response is associated with increased autophagy in the day 1 pregnant uterus.

\section{Regulation of autophagy by $\mathrm{P}_{4}$ or $\mathrm{E}_{2}$ in the OVX mouse uterus}

The above results indicate that autophagy shows a dynamic pattern of activation during early pregnancy. To examine whether ovarian steroid hormones affect autophagic activation in uterine cells, we used the OVX mouse model. Random cycling mice were OVX and given a dose of $\mathrm{P}_{4}(1 \mathrm{mg})$ or $\mathrm{E}_{2}(100 \mathrm{ng})$ after 12 days of rest. Uteri were removed at indicated time points after the injection. At the mRNA level, Becn1 (Atg6) expression slightly increases by $\mathrm{P}_{4}$ or $\mathrm{E}_{2}$. Minor changes in the expression of other genes were observed in response to each hormone (Supplementary Fig. S1, see section on supplementary data given at the end of this article). We then carried out western blotting of LC3, BECN1, and ATG5 in OVX mice treated with $\mathrm{P}_{4}$ or $\mathrm{E}_{2}$. As shown in Fig. $3, \mathrm{E}_{2}$ - or $\mathrm{P}_{4}$-treated mice showed decreased levels of LC3-II from $2 \mathrm{~h}$ postinjection compared with oil-injected control and reached the lowest level by $12 \mathrm{~h}$. A similar trend of ATG5 expression was observed. In contrast, BECN1 levels slightly increase by $24 \mathrm{~h}$ of $\mathrm{E}_{2}$ or $\mathrm{P}_{4}$ injection. Decreased level of LC3-II and ATG5 indicate that $\mathrm{E}_{2}$ and $\mathrm{P}_{4}$ suppress autophagic activation in the mouse uterus.

Next, to examine which cell types in the uterus of OVX mice exhibit autophagic response, immunofluorescence staining using anti-LC3 antibody was carried out on the cryosections of the uteri from oil- or $\mathrm{E}_{2}$-injected mice at $12 \mathrm{~h}$. As shown in Fig. 4A, LC3 puncta (green) were much

Published by Bioscientifica Ltd 
A
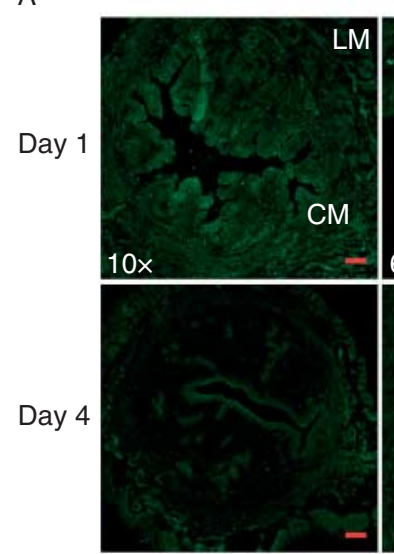

$100 \mu \mathrm{m}$
LC3

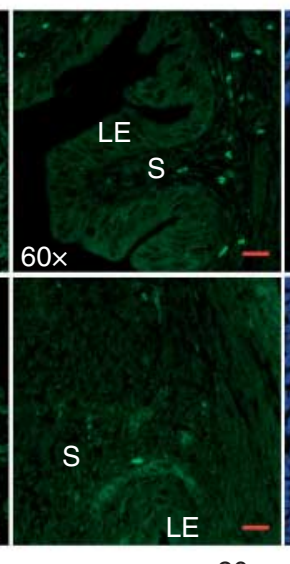

$20 \mu \mathrm{m}$
LC3 + DNA
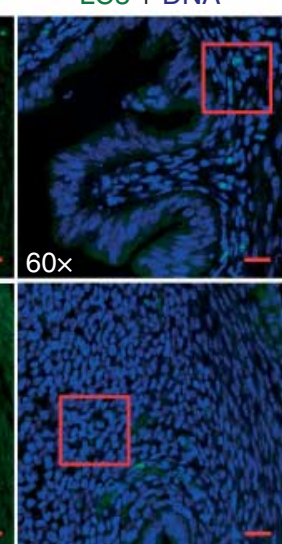

$20 \mu \mathrm{m}$
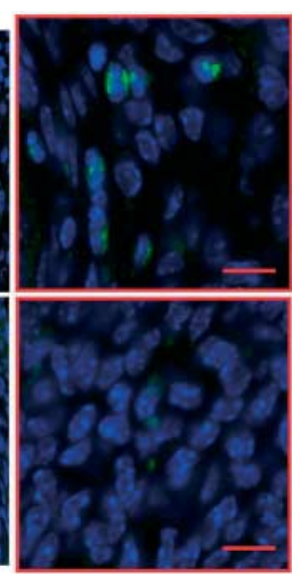

$10 \mu \mathrm{m}$
B

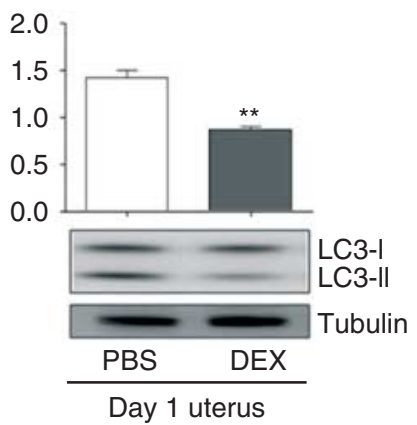

\section{Figure 2}

Autophagic activation in day 1 uteri and partial inhibition of autophagy by dexamethasone (DEX). (A) Cryosections of day 1 and day 4 pregnant uteri were subjected to immunofluorescence staining using anti-LC3 antibody. Alexa Fluor 488-conjugated secondary antibody was used and, therefore LC3 signal is shown in green. The sections were counterstained with TO-PRO-3-iodide (nuclei shown in blue). The area within the red rectangle is shown magnified in the right panel. LM, longitudinal muscle layer;

more prominent in the oil-treated group. Formation of LC3 puncta is mainly detected in the myometrium and at lower level in stromal cells. Myometrial and stromal localization of LC3 was not very visible in $\mathrm{P}_{4}$ - or $\mathrm{E}_{2}$-injected mice than in oil-treated mice. We also examined the uteri of GFP-LC3 transgenic mice to gain better imaging of LC3 puncta formation. OVX GFP-LC3 transgenic mice treated with oil or $\mathrm{E}_{2}$ were killed $12 \mathrm{~h}$ later. Uteri were subjected to cryosection and confocal live imaging. As shown in Fig. 4B, compared with generally high background level of GFP signal in $\mathrm{E}_{2}$-treated uteri, oil-treated uterine sections show numerous GFP puncta of various sizes (white arrows) in the stroma, luminal epithelium, and myometrium. An ultrastructural analysis confirms the presence of autophagic vacuoles in oil-treated uterus (Fig. 4C). As indicated by black arrows, numerous autophagic vacuoles in uterine cells of oil-treated OVX mice are clearly visible by transmission electron microscopy (TEM; Fig. 4C).

\section{Role for autophagy in glycogen breakdown in the uterus}

It was previously shown that OVX uteri deprived of steroid hormones for weeks have low glycogen content compared with $\mathrm{E}_{2}$-injected uteri (Ahmed-Sorour \& Bailey 1981). Thus, it is possible that hormone-deprived uteri might utilize accumulated glycogen as an energy source by the way of heightened autophagy. To examine whether autophagy is
$C M$, circular muscle layer; $S$, stroma; $L E$, luminal epithelium.

(B) Plug-positive mice received one i.p. injection of DEX $(2.5 \mathrm{mg} / \mathrm{kg}$ body weight) at $0800 \mathrm{~h}$ on day 1 of pregnancy to inhibit acute inflammatory response occurring in the uterus at mating. Control mice received $0.1 \mathrm{ml}$ PBS injection. Mice were killed at $2000 \mathrm{~h}$ and uteri were collected for western blotting. Effect of DEX on LC3-II conversion in day 1 uteri is shown. $* * P<0.01$.

involved in the regulation of glycogen content in uterine cells after OVX, we carried out a glycogen quantitation assay. We first confirmed that glycogen content is more than two times higher in $\mathrm{E}_{2}$-treated OVX uteri than oil-treated uteri (Fig. 5A). To examine whether heightened autophagy in OVX uteri is associated with reduced glycogen content, we gave a daily injection of 3-MA for 5 days before killing OVX mice. As shown in Fig. 5B, 3-MA injections significantly increases uterine glycogen content in OVX uteri, suggesting that heightened autophagy under hormone deprivation is associated with glycogen breakdown.

\section{Classical nuclear receptor is involved in the suppression of autophagic regulation by $E_{2}$ and $P_{4}$}

To examine whether hormonal regulation of autophagic activation is mediated via classical nuclear receptor signaling, ICI 182 780, an ER antagonist, was administered to OVX mice together with $\mathrm{E}_{2}$. ICI 182780 blocks the binding of estrogens to the nuclear ER (Das et al. 1997). ICI 182780 was co-injected with $\mathrm{E}_{2}$ into OVX mice, and uteri were assessed for LC3-II conversion. As shown in Fig. 6, the decreased level of LC3-II in $\mathrm{E}_{2}$-injected uteri was recovered in mice treated with both ICI 182780 and $\mathrm{E}_{2}$. This observation suggests that classical ER signaling is involved in autophagic regulation by $\mathrm{E}_{2}$. Furthermore, mifepristone, a PR antagonist (Das et al. 1995), reversed

Published by Bioscientifica Lto. 

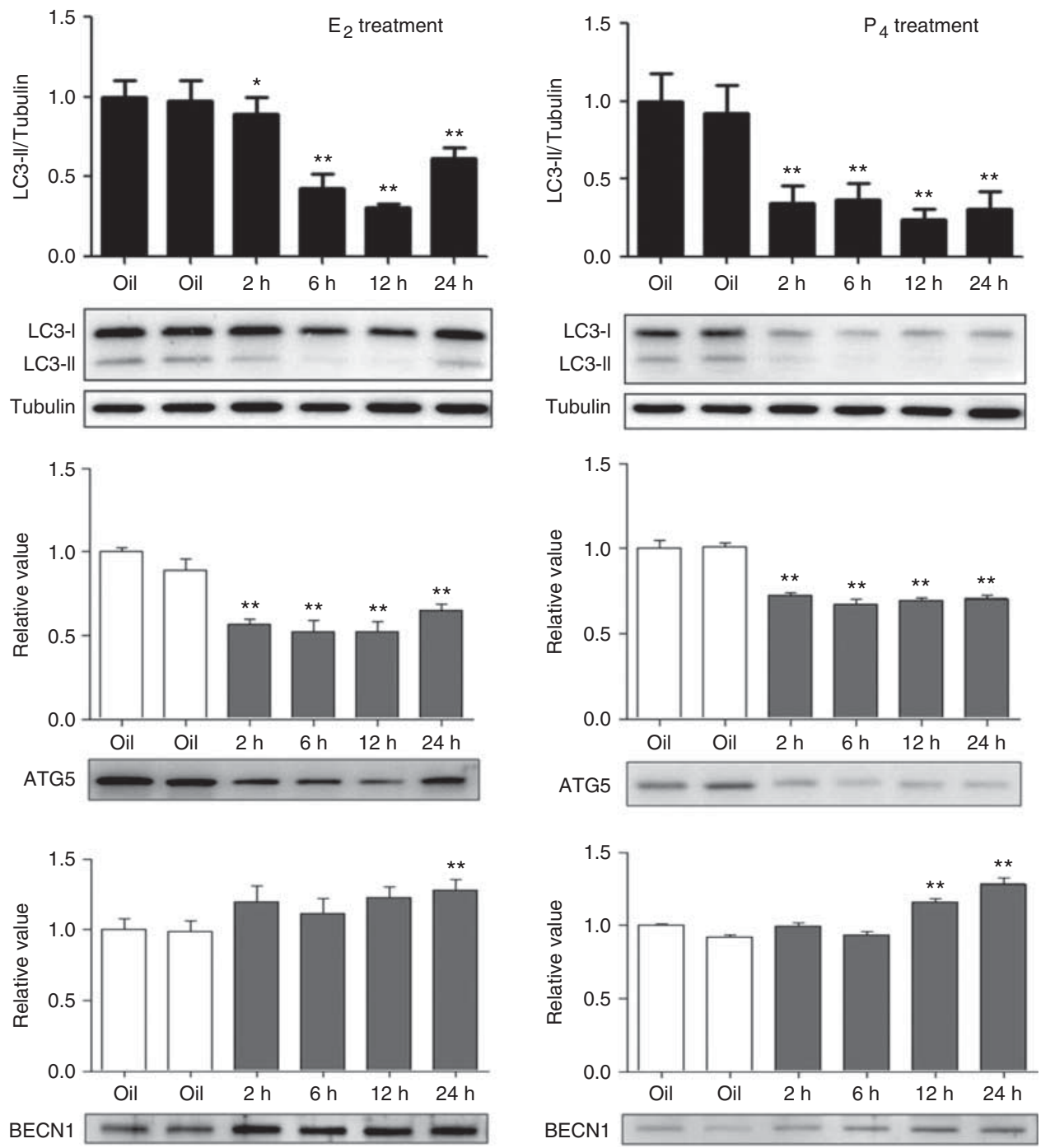

Figure 3

Autophagic activation assessed by western blotting of LC3, ATG5, and $B E C N 1$ in OVX mouse uteri by $E_{2}$ or $P_{4}$. A total of $50 \mu$ protein was loaded into each well. Western blotting of LC3-II, ATG5, and BECN1 were carried out. ECL intensity was quantified by LAS3000. The value of oil-injected control group was set as 1 and the relative values of the other groups

downregulation of autophagic activation by $\mathrm{P}_{4}$, suggesting the involvement of PR signaling in autophagic regulation in the mouse uterus (Fig. 6).

\section{Mouse target of rapamycin signaling mediates $\mathrm{E}_{2}$-induced suppression of autophagy in the uterus}

The signaling pathway of mouse target of rapamycin (mTOR) is an established suppressor of autophagic activation (Kapahi et al. 2010). $\mathrm{mTOR}$ is a seminal regulator of growth and its signaling is achieved by many factors including amino acids, growth factors, and hormones

http://joe.endocrinology-journals.org DOI: 10.1530/JOE-13-0449
(C) 2014 Society for Endocrinology Printed in Great Britain were plotted. Data show the mean of six independent experiments (LC3-II) or three experiments (ATG5 and BECN1). For ATG5, 56-kDa product of ATG5-ATG12 conjugate form is shown. Error bars represent S.D. Oil, sesame oil-treated control. ${ }^{*} 0.01<P<0.05 ; * * P<0.01$.

(Kapahi et al. 2010). Activation of mTOR signaling is inversely correlated with autophagy, which is activated during suboptimal conditions of low nutrients and energy sources (Glick et al. 2010). In the rat uterus, it has been shown that phosphorylation of mTOR is increased under the influence of $\mathrm{E}_{2}$ (Jaffer et al. 2009). We first examined whether the activation of mTOR, as assessed by the presence of phospho-mTOR (p-mTOR), is correlated with autophagic activation. As shown in Fig. 7A, the level of p-mTOR was inversely correlated with LC3-II accumulation in $\mathrm{E}_{2}$-injected mouse uteri. The level of p-mTOR was increased at 2 and $6 \mathrm{~h}$ post $\mathrm{E}_{2}$-injection and was slightly reduced from

Published by Bioscientifica Ltd. 


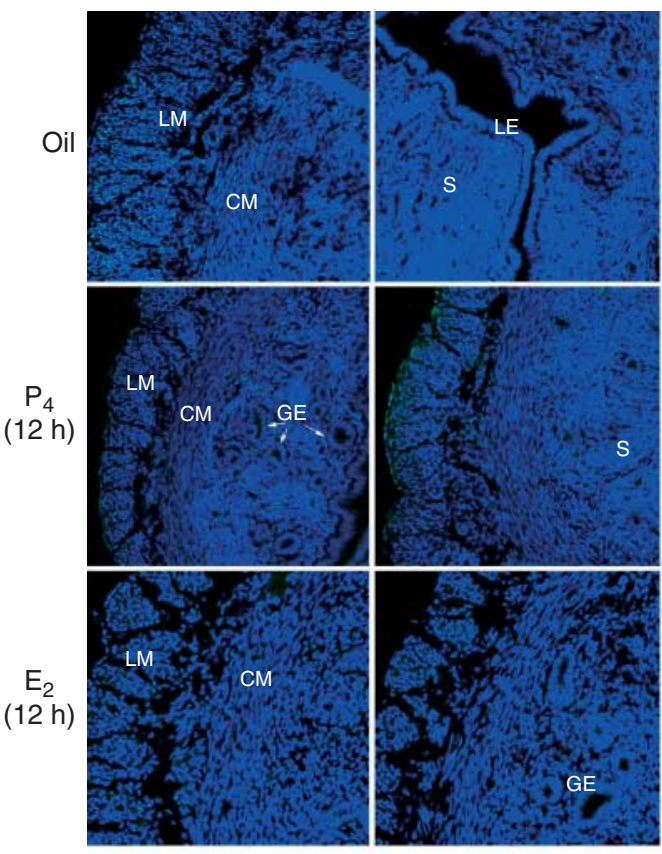

B GFP-LC3 transgenic mice
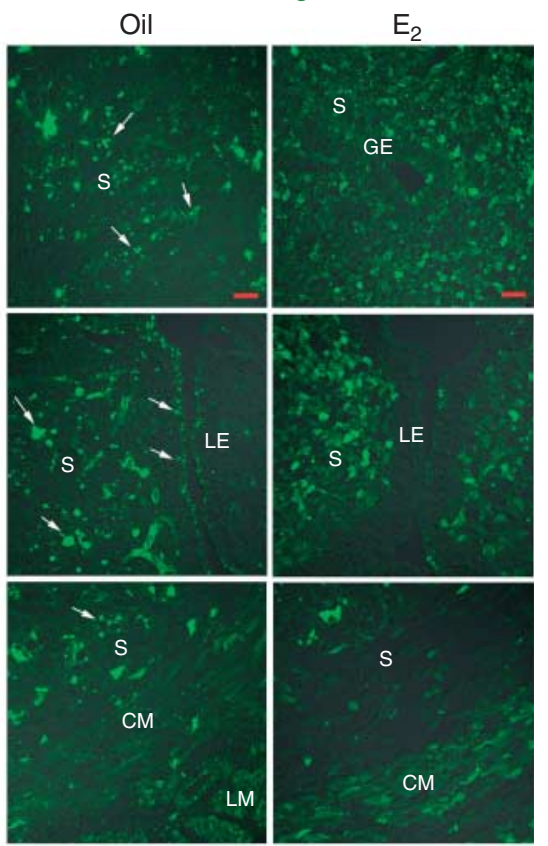

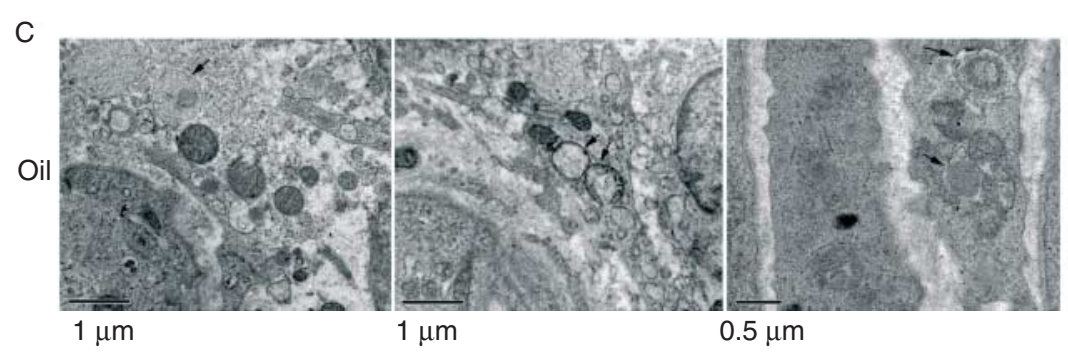

\section{Figure 4}

Autophagic activation in OVX mice. (A) LC3 immunofluorescence staining was carried out on uterine cryosections obtained at $12 \mathrm{~h}$ after oil or $\mathrm{E}_{2}$ injection. The sections were stained with anti-LC3 antibody and probed with an Alexa Fluor 488-conjugated secondary antibody (green). Nuclei were stained with TO-PRO-3-lodide (blue). Shown at $\times 40$. LM, longitudinal muscle layer; CM, circular muscle layer; S, stroma; LE, luminal epithelium; GE, glandular epithelium. (B) Uterine cryosections from OVX GFP-LC3 transgenic mice showing GFP-LC3 accumulation. GFP-LC3 transgenic mice

$12 \mathrm{~h}$ post-injection. In $\mathrm{P}_{4}$-treated OVX uteri, p-mTOR increases from $2 \mathrm{~h}$ post-injection and this level is maintained until $24 \mathrm{~h}$ (data not shown).

To determine whether the mTOR signaling pathway mediates the negative regulation of autophagy by steroid hormones, the mTOR inhibitor rapamycin was administered 30 min before injecting $\mathrm{E}_{2}$ to OVX mice. Uteri were collected at $6 \mathrm{~h}$ after hormone injection and western blotting was carried out using anti-p-mTOR and anti-LC3 antibody. As shown in Fig. 7B, rapamycin treatment reduced the level of p-mTOR in both oil- and $\mathrm{E}_{2}$-injected uteri, demonstrating the effectiveness of the drug. It also slightly were ovariectomized and rested for 12 days. Mice received sesame oil (vehicle, $0.1 \mathrm{ml}$ ) or $\mathrm{E}_{2}(100 \mathrm{ng} / 0.1 \mathrm{ml}$ oil) and were killed $12 \mathrm{~h}$ later. Uteri were cryosectioned at $5 \mu \mathrm{m}$ and observed under a confocal microscope. White arrows indicate GFP-LC3 puncta accumulation in the oil-treated uterus. Scale bar, $20 \mu \mathrm{m}$. (C) Transmission electron microscopic images of uterine sections from oil-injected OVX mice. Three representative images from different parts of uteri are shown. Black arrows indicate autophagic vacuoles at various stages.

increased autophagic activation by $\mathrm{E}_{2}$. In both oil- and $\mathrm{E}_{2}$-injected mice, LC3-II was detected at higher levels in the rapamycin-treated group than in control mice treated with DMSO. Although this result is not statistically significant, the downregulation of autophagy by $\mathrm{E}_{2}$ seems to be partially mediated by the mTOR pathway.

\section{Autophagic response in isolated mouse uterine cells}

The above results establish that ovarian steroid hormones regulate autophagic response in the mouse uterus. We examined whether a similar response is observed in

Published by Bioscientifica Ltd. 

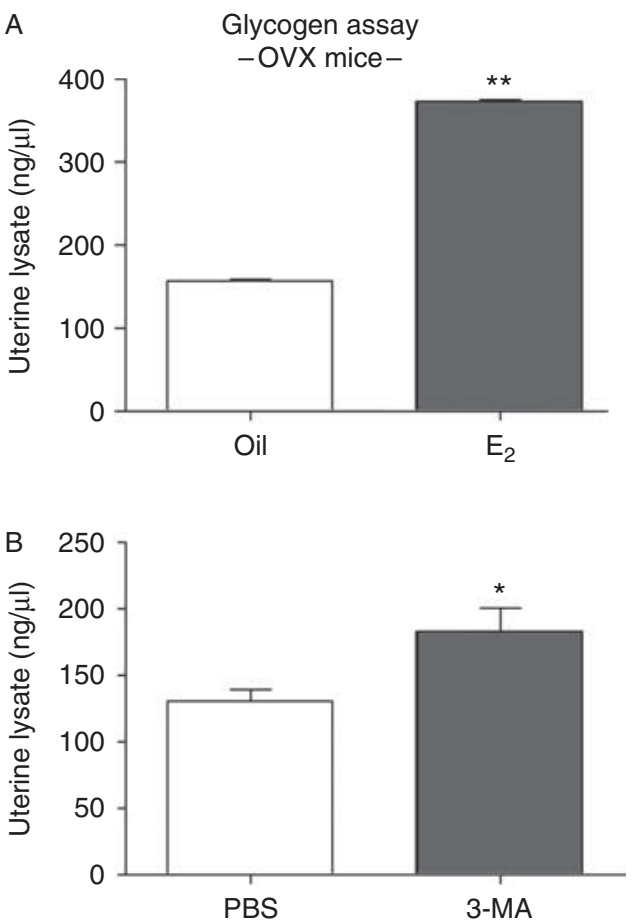

Figure 5

Effect of 3-MA injection on the uterine glycogen content. (A) Uteri from oil- or $\mathrm{E}_{2}$-injected mice were collected at $12 \mathrm{~h}$ and subjected to glycogen quantitation. One microliter of uterine lysate was used in duplicate for analysis $(n=3)$. (B) OVX mice received daily injections of 3-MA for 5 days (0.1 ml of $5 \mathrm{mM}$ solution in PBS). ${ }^{*} 0.01<P<0.05 ; * * P<0.01$.

primary cells isolated from the uterine stroma and epithelium (Chung \& Das 2011). Uterine epithelial cells and stromal cells were isolated from random cycling mice and cultured separately. To examine the effects of hormones without other influences originating from serum, the cells were first moved to HBSS and then treated with $\mathrm{P}_{4}$ or $\mathrm{E}_{2}$. LC3 western blotting was carried out in cells treated with $\mathrm{P}_{4}$ or $\mathrm{E}_{2}$. As shown in Fig. 8, primary uterine stromal cells show reduced autophagic activation when moved to HBSS. Under this condition, $\mathrm{P}_{4}$ did not affect LC3-II conversion while $\mathrm{E}_{2}$ slightly reduced it. In contrast, uterine epithelial cells showed reduced LC3-II conversion in response to both $\mathrm{P}_{4}$ and $\mathrm{E}_{2}$. These results suggest that isolated uterine epithelial or stromal cells show distinct responses to each hormone with respect to autophagic activation when isolated from the complex physiological uterine environment.

\section{Discussion}

$\mathrm{P}_{4}$ and estrogen are responsible for setting up the receptive uterus for embryo implantation. It is well established that these hormones, and their downstream signaling pathways, are the principal regulators of uterine cell growth and differentiation (Dey \& Lim 2006). In this study, we show that both $\mathrm{E}_{2}$ and $\mathrm{P}_{4}$ are negative regulators of autophagic activation in the mouse uterus. During normal pregnancy, autophagy is observed predominantly in stromal cells on day 1 of pregnancy when $E_{2}$ levels are high. However, autophagy remains at a low level afterwards (Figs 1 and 2). In OVX mice deprived of steroid hormones, autophagic activation is highest in the
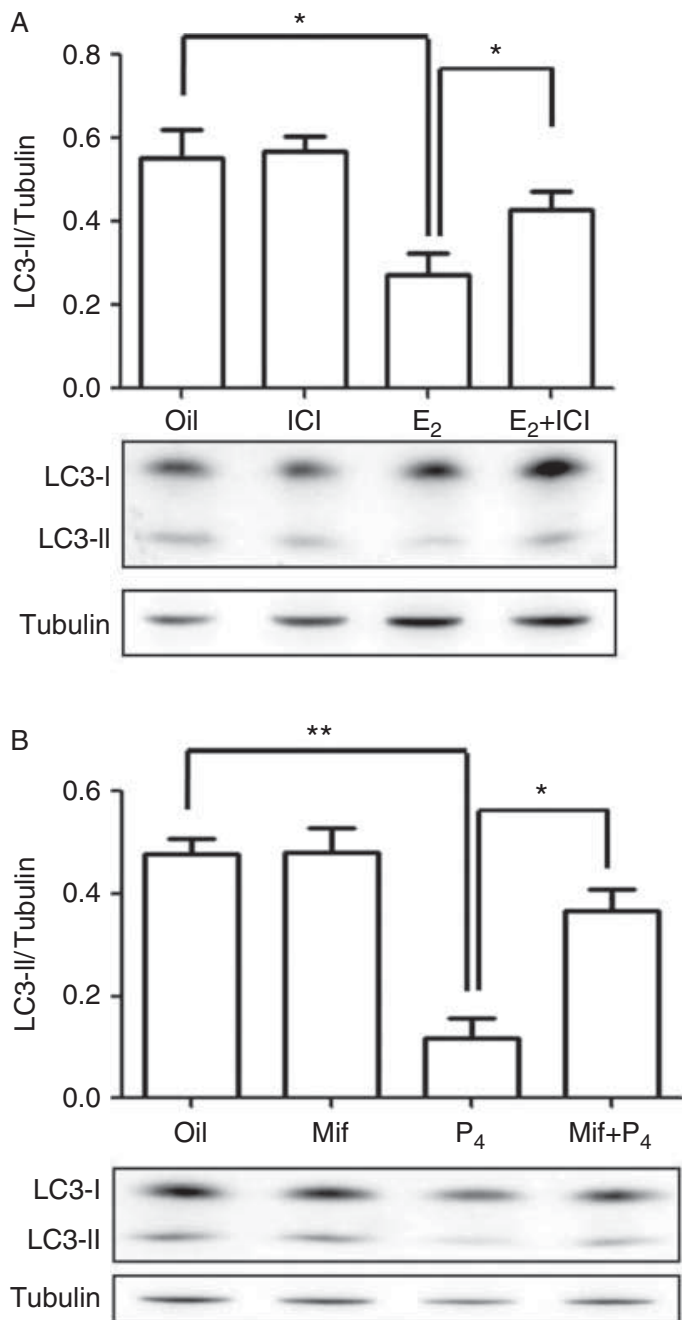

\section{Figure 6}

Involvement of classical nuclear hormone receptors in the regulation of autophagic response in the mouse uterus. Western blot analysis was carried out to examine the effect of ER or PR antagonist on autophagic regulation. (A) OVX mice received oil, ICI 182780 alone $(0.5 \mathrm{mg} / 0.1 \mathrm{ml}), \mathrm{E}_{2}$ alone (100 ng/0.1 ml), or $\mathrm{ICl}$ and $E_{2}$ together. (B) OVX mice received oil, mifepristone (Mif) alone (1 mg/0.1 ml), $\mathrm{P}_{4}$ alone $(1 \mathrm{mg} / 0.1 \mathrm{ml})$, or mifepristone and $\mathrm{P}_{4}$ together. The ratio of $\mathrm{LC} 3-\mathrm{II}$ form/ $\alpha \beta$-tubulin signals was used to analyze the data. A total of $50 \mu \mathrm{g}$ protein was loaded on each well. The experiment was repeated three times. ${ }^{*} 0.01<P<0.05 ;{ }^{*} P<0.01$.

Published by Bioscientifica Ltd. 

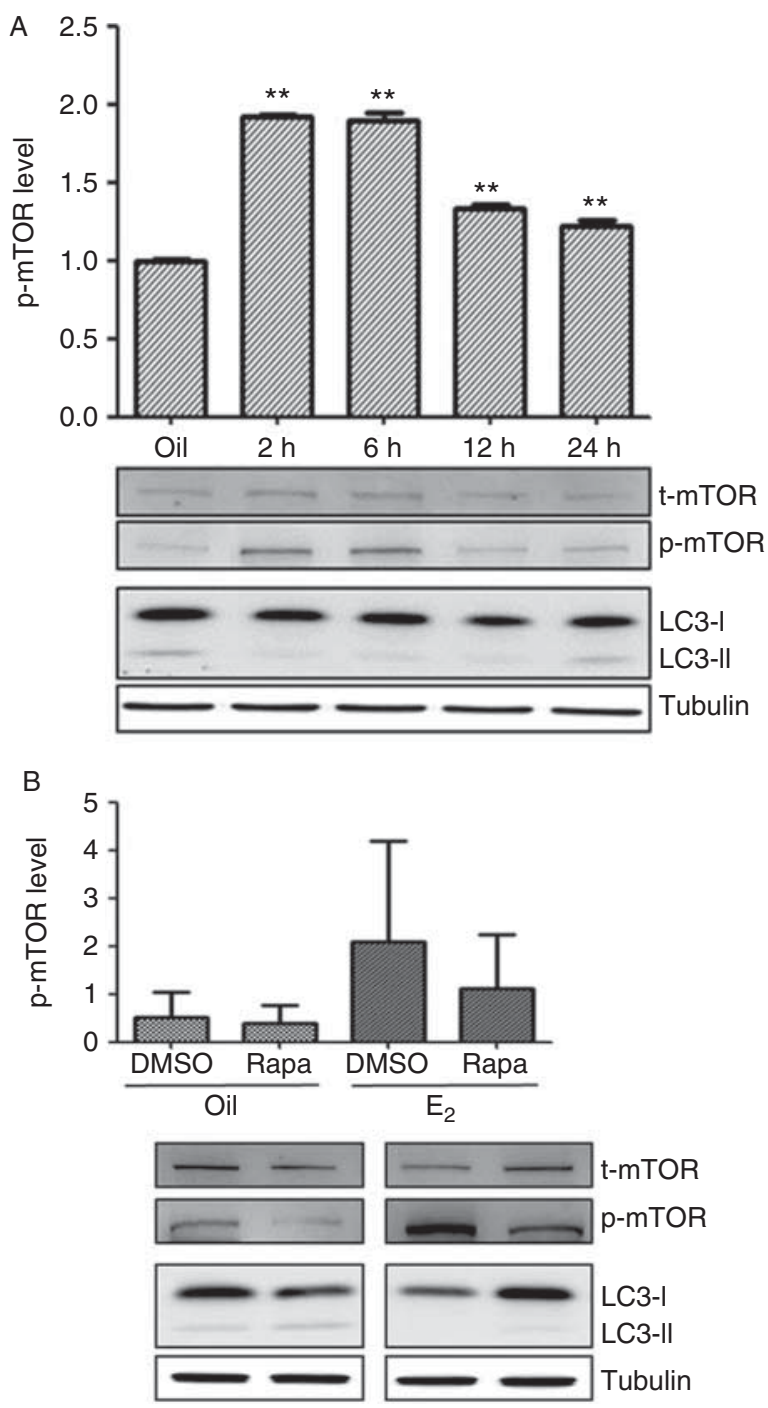

\section{Figure 7}

Involvement of the mTOR-signaling pathway in $\mathrm{E}_{2}$-suppressed autophagic activation in mouse uteri. (A) Western blot analyses of total mTOR (t-mTOR), activated form of mTOR (p-mTOR), and LC3 in OVX uteri treated with $E_{2}$. (B) Rapamycin, an inhibitor of mTOR, was given to OVX mice before $E_{2}$ injection. Mice were killed at $6 \mathrm{~h}$ post- $E_{2}$ injection. Rapamycin treatment increases LC3-II accumulation in both oil- and $E_{2}$-injected uteri, suggesting a negative regulation of autophagy by mTOR. This experiment was repeated three times. ${ }^{*} P<0.01$.

myometrial and stromal compartments and in the epithelial border of the uterus (Fig. 4B). $\mathrm{E}_{2}$ or $\mathrm{P}_{4}$ injection to OVX mice reduces the level of autophagic activation in the uterus (Fig. 3) and mTOR signaling partially mediates $\mathrm{E}_{2}$-induced suppression of autophagy (Fig. 7). The suppression of autophagy by $\mathrm{E}_{2}$ and $\mathrm{P}_{4}$ is not prominent in isolated uterine stromal cells (Fig. 8), although a low degree of suppression was noted in the isolated uterine epithelial cells. These results suggest that complex physiological mechanisms underlie the suppression of autophagy by ovarian steroid hormones in vivo. Increased autophagy in the day 1 pregnant uterus is reduced when DEX is administered, suggesting that acute inflammatory response at mating is a possible inducer of autophagy on this day. Increased autophagy in OVX uteri compared with $\mathrm{E}_{2^{-}}$or $\mathrm{P}_{4}$-injected uteri is associated with low glycogen content in the uterus, as 3-MA injection to OVX mice increased uterine glycogen content. Thus, one possible function of autophagy in hormone-derived uterine environment is glycogen breakdown to provide energy source to uterine cells.

Newborn Atg5 or Atg7 knockout mice die within a day of birth, partly owing to reduced levels of circulating amino acids in the blood (Kuma et al. 2004, Komatsu et al. 2005). Glycogen is also an important energy source for tissues during the neonatal period. Glycogen granules are found abundantly within autophagosomes of various neonatal tissues (Phillips et al. 1967, Schiaffino \& Hanzlikova 1972), and glucose produced by autophagy can be utilized in the working muscles of neonates (Schiaffino et al. 2008). OVX uteri deprived of steroid hormones for weeks have low glycogen content compared with cycling or hormone-treated mice, whereas $\mathrm{E}_{2}$-injected uteri accumulate glycogen at levels several times higher than OVX uteri (Ahmed-Sorour \& Bailey 1981). Our results demonstrating that 3-MA injection increases uterine glycogen content in OVX uteri well supports the

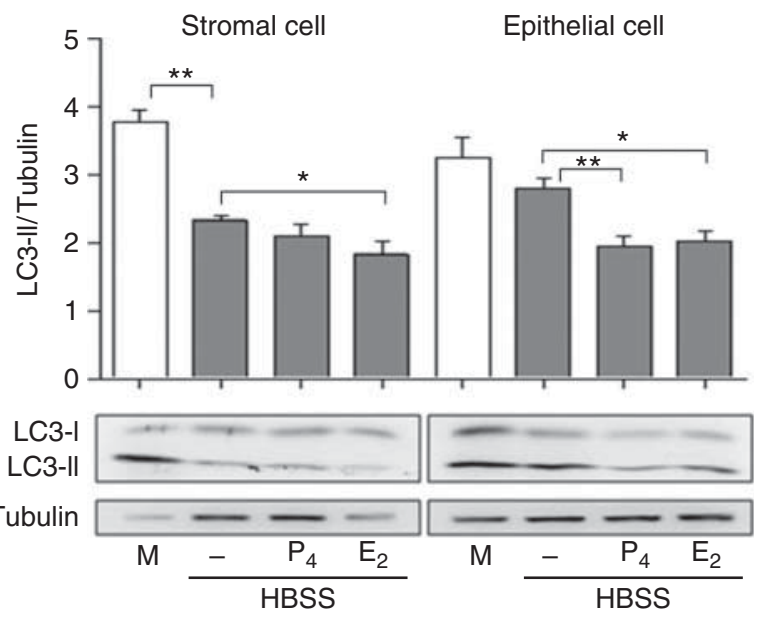

Figure 8

Western blotting of LC3 in primary uterine epithelial and stromal cells treated with $\mathrm{E}_{2}$ or $\mathrm{P}_{4}$. Uterine epithelial cells and stromal cells were isolated from 5-6 random cycling mice and cultured separately. The cells were cultured in media until they reached $\sim 80 \%$ confluence. The cells were incubated in phenol red-free HBSS for $1 \mathrm{~h}$ and then treated with $\mathrm{P}_{4}$ or $\mathrm{E}_{2}$ for $2 \mathrm{~h}$. This experiment was repeated three times with cells from different mice. $M$, media-treated group; -, control group treated with vehicle (ethanol); $\mathrm{P}_{4}, 1 \mu \mathrm{M} \mathrm{P}_{4} ; \mathrm{E}_{2}, 10 \mathrm{nM} \mathrm{E}_{2}$. ${ }^{*} 0.01<P<0.05 ; * * P<0.01$. 
hypothesis that autophagy serves the function of glycogen breakdown during hormone deprivation. We compared the accumulation of LC3-II in OVX mice that were deprived of steroids for 2 weeks, 8 weeks, and 8 months, and observed that there was no significant increase in the level of autophagy in OVX mice deprived of hormones for longer periods of time (data not shown). Thus, it is possible that autophagy seems to be kept in check without being overly exaggerated under long-term scarcity of hormones in OVX mice via other mechanisms.

Immunofluorescence staining of LC3 indicates that autophagic activation is prominent in the subsets of stromal cells of day 1 pregnant uteri (Fig. 2). Given that $E_{2}$ levels are at their highest on this day of pregnancy due to the preovulatory surge of $\mathrm{E}_{2}$, high autophagic activation on day 1 does not seem to be under the direct regulation of $\mathrm{E}_{2}$. Thus, we hypothesize a distinct mechanism of stimulation in pregnant uteri. LC3 accumulation is strong in the stroma but not in the myometrium of the day 1 pregnant uterus, and this pattern is different to the observation we report in OVX uteri (Fig. 4). One distinguishable event that occurs on day 1 of pregnancy is the infiltration of immune cells in response to the production of various cytokines in the uterus (McMaster etal. 1992). This inflammatory response is mainly due to semen deposition during mating (Robertson et al. 1994). Tumor necrosis factor $\alpha$ (TNF $\alpha$ ), interleukin $1 \alpha$ (IL1 $1 \alpha)$, IL1 $\beta$, and granulocyte-macrophage colony-stimulating factor (GM-CSF) are expressed in stromal cells of day 1 uteri (McMaster et al. 1992, Tremellen et al. 1998), and their localization patterns resemble that of LC3 in the stromal cells (McMaster et al. 1992; Fig. 2). IL1 $\alpha$ and IL1 $\beta$ are among the cytokines that induce autophagosome formation during inflammatory response (Harris 2013). Thus, it is possible that heightened autophagic response in day 1 pregnant uteri is associated with increased inflammatory response on this day due to mating and clearance of semen. Indeed, DEX treatment to day 1 pregnant mice led to decreased LC3-II conversion in the uterus (Fig. 2B), solidifying our hypothesis that autophagic activation observed in day 1 pregnant uteri and in OVX uteri is of distinct nature, which seems to involve different inducers and regulators.

Among autophagy proteins we investigated herein, BECN1 showed a different pattern of regulation by hormones in the uterus (Fig. 3 and Supplementary Fig. S1). BECN1 forms a complex with VPS15 and other proteins to regulate autophagosome formation. BECN1-containing complex, however, plays diverse functions that are unrelated to autophagy (Wirawan et al. 2012). Involvement of BECN1 in various cellular processes, such as endocytosis, cytokinesis, and phagocytosis, has been reported (Wirawan et al. 2012). Whether BECN1 plays such non-autophagy functions in the uterus requires further investigation.

Numerous investigations have provided evidence that anti-estrogenic effects are associated with autophagic cell death in breast cancer cells (Bursch et al. 1996, de Medina et al. 2009). In mammary epithelial cells, estrogen and $P_{4}$ exhibit a stimulatory effect on autophagy, which accompanies suppression of the mTOR pathway (Sobolewska et al. 2009). In osteoblasts, it has been shown that estradiol enhances autophagy via promoting the dephosphorylation of mTOR (Yang et al. 2013).

Isolated uterine stromal cells do not seem to respond to $\mathrm{E}_{2}$ and $\mathrm{P}_{4}$ in vitro, while uterine epithelial cells show reduced autophagy by $\mathrm{E}_{2}$ or $\mathrm{P}_{4}$ (Fig. 8). Subtle autophagic response of isolated uterine epithelial or stroma cells to $\mathrm{E}_{2}$ and $\mathrm{P}_{4}$ may reflect the complex nature of the inductive mechanism of autophagy in vivo. Accumulating evidence, together with the present investigation, suggests that the regulation of autophagy by estrogen or $\mathrm{P}_{4}$ exhibits a tissue type- or cell type-specific patterns that reflect differences in hormone responsiveness and in subcellular signaling mediator pools. Our present work shows that the major ovarian steroid hormones are negative regulators of autophagy in the mouse uterus.

\section{Supplementary data}

This is linked to the online version of the paper at http://dx.doi.org/10.1530/ JOE-13-0449.

\section{Declaration of interest}

The authors declare that there is no conflict of interest that could be perceived as prejudicing the impartiality of the research reported.

\section{Funding}

This work was supported by the National Research Foundation of Korea (NRF) grant funded by the Korea government (MEST) (No. 2011-0016513).

\section{Acknowledgements}

The authors thank members of the Lim laboratory for their constant support.

\section{References}

Ahmed-Sorour H \& Bailey CJ 1981 Role of ovarian hormones in the long-term control of glucose homeostasis, glycogen formation and gluconeogenesis. Annals of Nutrition \& Metabolism 25 208-212. (doi:10.1159/000176496)

Boya P, Reggiori F \& Codogno P 2013 Emerging regulation and functions of autophagy. Nature Cell Biology 15 713-720. (doi:10.1038/ncb2788)

Bursch W, Ellinger A, Kienzl H, Torok L, Pandey S, Sikorska M, Walker R \& Hermann RS 1996 Active cell death induced by the anti-estrogens

Published by Bioscientifica Ltd. 
tamoxifen and ICI 164384 in human mammary carcinoma cells (MCF-7) in culture: the role of autophagy. Carcinogenesis 17 1595-1607. (doi:10.1093/carcin/17.8.1595)

Choi J, Jo M, Lee E, Oh YK \& Choi D 2012 The role of autophagy in human endometrium. Biology of Reproduction 86 70. (doi:10.1095/biolreprod. 111.096206)

Chung D \& Das SK 2011 Mouse primary uterine cell coculture system revisited: ovarian hormones mimic the aspects of in vivo uterine cell proliferation. Endocrinology 152 3246-3258. (doi:10.1210/en.2011-0223)

Das SK 2009 Cell cycle regulatory control for uterine stromal cell decidualization in implantation. Reproduction 137 889-899. (doi:10.1530/REP-08-0539)

Das SK, Chakraborty I, Paria BC, Wang XN, Plowman G \& Dey SK 1995 Amphiregulin is an implantation-specific and progesterone-regulated gene in the mouse uterus. Molecular Endocrinology 9 691-705. (doi:10.1210/mend.9.6.8592515)

Das SK, Taylor JA, Korach KS, Paria BC, Dey SK \& Lubahn DB 1997 Estrogenic responses in estrogen receptor- $\alpha$ deficient mice reveal a distinct estrogen signaling pathway. PNAS 94 12786-12791. (doi:10.1073/pnas.94.24.12786)

Dey SK \& Lim H 2006 Implantation. In Knobil and Neill's Physiology of Reproduction, pp 147-188. Ed Jimmy D Neill. Philadelphia: Elsevier.

Dey SK, Lim H, Das SK, Reese J, Paria BC, Daikoku T \& Wang H 2004 Molecular cues to implantation. Endocrine Reviews 25 341-373. (doi:10.1210/er.2003-0020)

Geng J \& Klionsky DJ 2008 The Atg8 and Atg12 ubiquitin-like conjugation systems in macroautophagy. Protein modifications: beyond the usual suspects' review series. EMBO Reports 9 859-864. (doi:10.1038/embor.2008.163)

Glick D, Barth S \& Macleod KF 2010 Autophagy: cellular and molecular mechanisms. Journal of Pathology 221 3-12. (doi:10.1002/path.2697)

Harris J 2013 Autophagy and IL-1 family cytokines. Frontiers in Immunology 4 83. (doi:10.3389/fimmu.2013.00083)

Jaffer S, Shynlova O \& Lye S 2009 Mammalian target of rapamycin is activated in association with myometrial proliferation during pregnancy. Endocrinology 150 4672-4680. (doi:10.1210/en.2009-0419)

Kapahi P, Chen D, Rogers AN, Katewa SD, Li PW, Thomas EL \& Kockel L 2010 With TOR, less is more: a key role for the conserved nutrientsensing TOR pathway in aging. Cell Metabolism 11 453-465. (doi:10.1016/j.cmet.2010.05.001)

Kim J, McKinley L, Siddiqui J, Bolgos GL \& Remick DG 2004 Prevention and reversal of pulmonary inflammation and airway hyperresponsiveness by dexamethasone treatment in a murine model of asthma induced by house dust. American Journal of Physiology. Lung Cellular and Molecular Physiology 287 L503-L509. (doi:10.1152/ajplung.00433.2003)

Klionsky DJ, Abdalla FC, Abeliovich H, Abraham RT, Acevedo-Arozena A, Adeli K, Agholme L, Agnello M, Agostinis P, Aguirre-Ghiso JA et al. 2012 Guidelines for the use and interpretation of assays for monitoring autophagy. Autophagy 8 445-544. (doi:10.4161/auto.19496)

Komatsu M \& Ichimura Y 2010 Physiological significance of selective degradation of p62 by autophagy. FEBS Letters 584 1374-1378. (doi:10.1016/j.febslet.2010.02.017)

Komatsu M, Waguri S, Ueno T, Iwata J, Murata S, Tanida I, Ezaki J, Mizushima N, Ohsumi Y, Uchiyama Y et al. 2005 Impairment of starvation-induced and constitutive autophagy in Atg7-deficient mice. Journal of Cell Biology 169 425-434. (doi:10.1083/jcb.200412022)

Komatsu M, Waguri S, Koike M, Sou YS, Ueno T, Hara T, Mizushima N, Iwata J, Ezaki J, Murata S et al. 2007 Homeostatic levels of p62 control cytoplasmic inclusion body formation in autophagy-deficient mice. Cell 131 1149-1163. (doi:10.1016/j.cell.2007.10.035)

Kuma A, Hatano M, Matsui M, Yamamoto A, Nakaya H, Yoshimori T, Ohsumi Y, Tokuhisa T \& Mizushima N 2004 The role of autophagy during the early neonatal starvation period. Nature $\mathbf{4 3 2} 1032-1036$. (doi:10.1038/nature03029)

Lee JE, Oh HA, Song H, Jun JH, Roh CR, Xie H, Dey SK \& Lim HJ 2011 Autophagy regulates embryonic survival during delayed implantation. Endocrinology 152 2067-2075. (doi:10.1210/en.2010-1456)

Levine B \& Klionsky DJ 2004 Development by self-digestion: molecular mechanisms and biological functions of autophagy. Developmental Cell 6 463-477. (doi:10.1016/S1534-5807(04)00099-1)

Marino G, Salvador-Montoliu N, Fueyo A, Knecht E, Mizushima N \& Lopez-Otin C 2007 Tissue-specific autophagy alterations and increased tumorigenesis in mice deficient in Atg4C/autophagin-3. Journal of Biological Chemistry 282 18573-18583. (doi:10.1074/jbc.M701194200)

McMaster MT, Newton RC, Dey SK \& Andrews GK 1992 Activation and distribution of inflammatory cells in the mouse uterus during the preimplantation period. Journal of Immunology 148 1699-1705.

de Medina P, Silvente-Poirot S \& Poirot M 2009 Tamoxifen and AEBS ligands induced apoptosis and autophagy in breast cancer cells through the stimulation of sterol accumulation. Autophagy 5 1066-1067. (doi:10.4161/auto.5.7.9820)

Mizushima N, Yamamoto A, Matsui M, Yoshimori T \& Ohsumi Y 2004 In vivo analysis of autophagy in response to nutrient starvation using transgenic mice expressing a fluorescent autophagosome marker. Molecular Biology of the Cell 15 1101-1111. (doi:10.1091/mbc.E03-09-0704)

Oh HA, Kwon S, Choi S, Shin H, Yoon KH, Kim WJ \& Lim HJ 2013 Uncovering a role for endocannabinoid signaling in autophagy in preimplantation mouse embryos. Molecular Human Reproduction 19 93-101. (doi:10.1093/molehr/gas049)

Phillips MJ, Unakar NJ, Doornewaard G \& Steiner JW 1967 Glycogen depletion in the newborn rat liver: an electron microscopic and electron histochemical study. Journal of Ultrastructure Research 18 142-165. (doi:10.1016/S0022-5320(67)80236-3)

Robertson SA, Seamark RF, Guilbert LJ \& Wegmann TG 1994 The role of cytokines in gestation. Critical Reviews in Immunology 14 239-292. (doi:10.1615/CritRevImmunol.v14.i3-4.30)

Schiaffino S \& Hanzlikova V 1972 Autophagic degradation of glycogen in skeletal muscles of the newborn rat. Journal of Cell Biology 52 41-51. (doi:10.1083/jcb.52.1.41)

Schiaffino S, Mammucari C \& Sandri M 2008 The role of autophagy in neonatal tissues: just a response to amino acid starvation? Autophagy 4 727-730.

Sobolewska A, Gajewska M, Zarzynska J, Gajkowska B \& Motyl T 2009 IGF-I, EGF, and sex steroids regulate autophagy in bovine mammary epithelial cells via the mTOR pathway. European Journal of Cell Biology 88 117-130. (doi:10.1016/j.ejcb.2008.09.004)

Tremellen KP, Seamark RF \& Robertson SA 1998 Seminal transforming growth factor $\beta 1$ stimulates granulocyte-macrophage colonystimulating factor production and inflammatory cell recruitment in the murine uterus. Biology of Reproduction 58 1217-1225. (doi:10.1095/ biolreprod58.5.1217)

Whitten WK 1958 Modification of the oestrous cycle of the mouse by external stimuli associated with the male; changes in the oestrous cycle determined by vaginal smears. Journal of Endocrinology 17 307-313. (doi:10.1677/joe.0.0170307)

Wirawan E, Lippens S, Vanden Berghe T, Romagnoli A, Fimia GM, Piacentini M \& Vandenabeele P 2012 Beclin1: a role in membrane dynamics and beyond. Autophagy 8 6-17. (doi:10.4161/auto.8.1.16645)

Yang Z \& Klionsky DJ 2010 Eaten alive: a history of macroautophagy. Nature Cell Biology 12 814-822. (doi:10.1038/ncb0910-814)

Yang YH, Chen K, Li B, Chen JW, Zheng XF, Wang YR, Jiang SD \& Jiang LS 2013 Estradiol inhibits osteoblast apoptosis via promotion of autophagy through the ER-ERK-mTOR pathway. Apoptosis 18 1363-1375. (doi:10.1007/s10495-013-0867-x)

Received in final form 30 December 2013

Accepted 17 January 2014

Accepted Preprint published online 17 January 2014 